Vega, was next looked at: the only notable thing be- $r$

ing that certain little stars between the two pairs, hard to see, evels in a dark night, were easy and al-
most conspicuous, notwithstanding the moonlight.

The "Ring nebula" was very pretty, but a mere
pale ghost of what it would have been on a moonless

sky. by putting the large star out of sight, we could see a little companion which Mr. A. G. Clark has just dis$12^{\prime \prime}$ distant from the larger star of the pair. Probably it can be seen by some of the other large telescope magnitude smaller than Winnecke's companion of A number of other objects were looked at, but nothing that calls for special notice here. The elder Clark remained present during the whole every object, even when the position required was such as to cramp and try younger limbs and muscles. Hi eye seems to have lost little of its original keenness permit him to do much actual labor. But what a ste from his first three inch glass made for Dr. Wells,
Salem (in 1850. I think), to his great three foot lens! Toward midnight, when the time came to leave off Toward midnight, when the time came to leave off
work, the telescope was turned vertically, object glass the lens was about eighteen inches from the ground baggage truck was then rolled under the telescope, and, by a stout serew underneath, the floor of the truck was
raised until it touched the cell which holds the lenses. On loosening the serews which hold the cell to the tube, the weight of the object glass, about $750 \mathrm{lb}$., settles
down upon the truck; and when everything is clear, three men haul it away along a plank walk, and little fireproof building where the grinding and polishing are done.

While the making of the great lens has gone on thus rapidly and successfully since the crown glass disk wa just met a serious setback in the matter of the "photographic corrector," which was to go with it, and fit it for astronomical photography. The disk out of
which this lens was to be inade was received from Feil last spring. Examination by polarized light showe that the glass was under a severe internal strain, due fied the maker of the fact, and told him that they feared the disk would not bear working. The maker, proceed at his risk, which they did. The upshot of it was that, a few days ago, the disk burst into three pieces while on the grinding tool ; and so, of course,
that part of the work will have to be postponed until new disk can be obtained; how long that will take This will not, however, delay th

strument. Its mounting is already well under way in the shops of Warner \& S wazey, at Cleveland; and, un ess there is some unexpected delay about the observathat, within a year from now, this monstrous piece of astronomical artillery will have opened fire upon the Holden, it will prove effective.

\section{ON A METEORIC IRON FROM SOUTH} CAROLINA

By William Earl Hidden.

THE meteorite here described and illustrated "was found, in the vear 1857, in the north west corner of Lau-
rens County, South Carolina, and was deposited in the cabinet of the Laurensville Female College, at Laurens New Orleans Exposition of 1884-85, where it furmed a part of the State exhibit of South Carolina." The writer first saw it there, and was enabled, through the kindness of the State Commissioner, to gain possessio An analysis of a small piece cut from the mass with
some difficulty, yielded Mr. J. B. Mackintosh the folsowe difficulty, yielded Mr. J. B. Mackintosh the fol 0.87 ; phosphorus, $0.16=99 \cdot 70$; sulphur and carbon in traces. Thus it is seen that in composition this mass of meteoric iron is of unusual interest, the perhigh. 1 shows the mass in its exact natural size, and exhibits well the natural appearance of the Widmann statten figures brought out on this surface by etching
with dilute nitric acid. The rough surface, surround ing the smooth, countersunk, etched panel, was purposely left in its original condition, so that the homogeneity of the mass could be readily seen. The exten-
sion of a few lines of the panel surface can be traced running over the rough exterior, and other lines are
seen to be parallel when not continuous. The very apparent tendeney of the perpendicular lines of this figure to form a right angle with the upper and lower sides, and a parallelisin to the right and left hand edges, confirms the belief that we have, in this mass'of
meteoric iron, a well marked relation to a cuboidal form; a shape very rarely, if ever before, observed in masses

Since the illustrations are made by a photo-engrav with satisfaction, knowing that nothing is misrepresented, or incorrectly drawn.
On five sides of this mass, an angle of $90^{\circ}$ seemed to be very closely approximated. which tends to prove the form to be cuboidal by design rather than by acly pitted, or they presented the appearance of having been broken apart, by occult causes, from parts of th sibly, completing the cuboidal form on all sides. Fig. 2 represents part of a surface parallel to Fig. 1
but distant more than an inch from it, at the back but distant more than an inch from it, at the back of
the mass. It is placed on the page in its natural relative position to Fig. 1, the lines in both figures
being parallel.
Of special interest is the broad double line on the
right-hand side of Fig. 2. From it, pointing upward
at an angle of about $70^{\circ}$ from the perpendicular, are
seen lines, diverging right and left, at the same incli-
nation, thus showing that twinning has oceurred in this
iron, parallel to an octahedral face. This broad line
the writer has traced over the entire exterior of the
mass, and identified it with the line in Fig. 1, situated
two centimeters from the right-hand edge of the panel.
The homogeneity is thereby clearly proved.

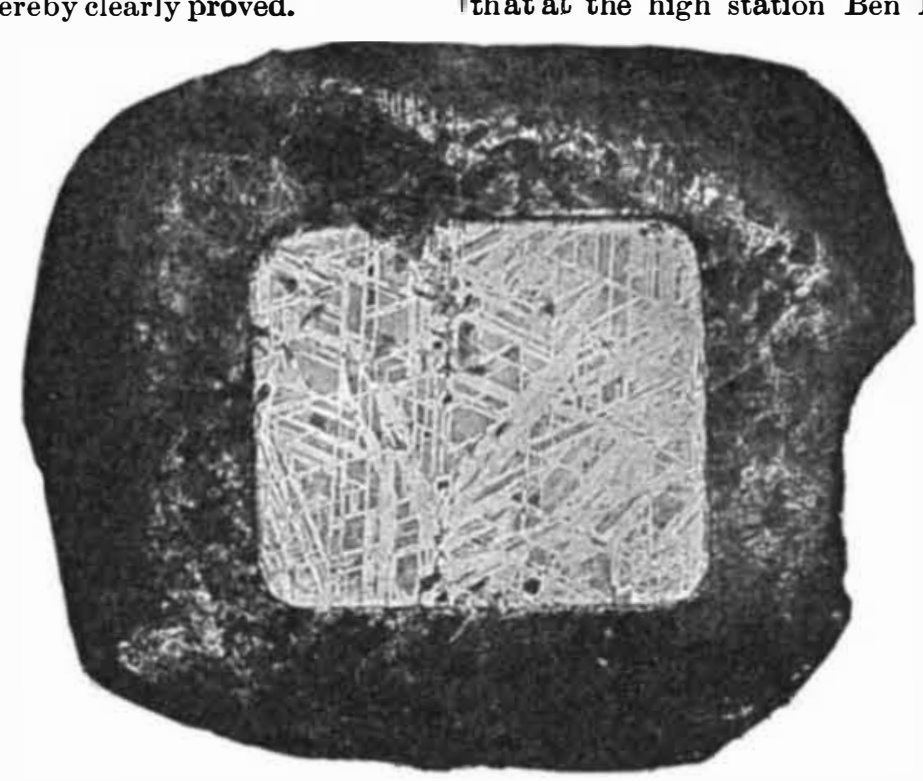

FIG. 1.-Meteoric Iron (Cuboidal), from Laurens County, S. C. (Natural size.)

The sharpness and general perfection of the Wid-
mannstätten figures in this iron have seldom been equaled.

ngles to the lower right-hand edge of Fig. 1, and is, in the writer's opinion, th $€$ place of impact when this mass
struck the earth. It is of interest to compare the fineness of these lines with those of the other figures; the
parallelism of the lines to the longer straight edge-the
cuhoidal face-is also noteworthy.

The presence of hydrogen was proved by simply rubbing powdered sulphur over the smoothed surfaces
when, instantly, the disagreeable odor of hydrogen

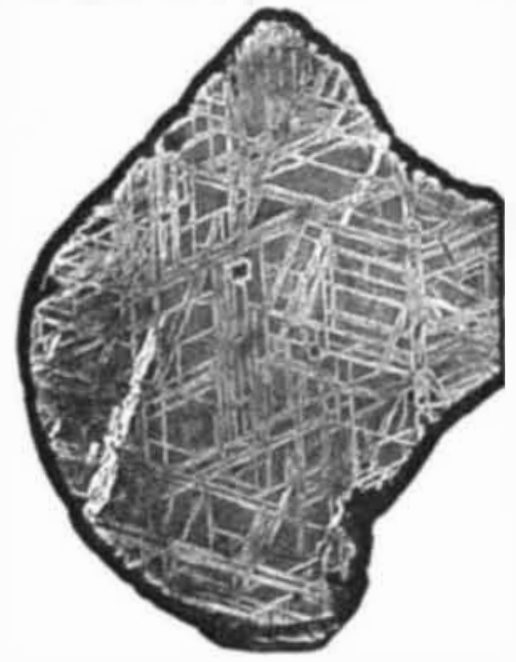

FiG. 2.-Widmannstatten Lines on the Lauren

County, S. C., Meteoric Iron. (Natural size.)

sulphide was made noticeable. In the action of nitric as graphite.
Lawrencite (ferrous chloride) was noticed in the solid state, and in Fig. 2 the dark, rhomboidal spots repreThis the situation of this rare mineral in the mass.
This approaches that of Babb's Mill (Tennessee) and of Kokomo (Indiana) in its high nicke percentages, and in the fine development of the Wid
inannstatten figures to that of Smith Mountain (North Carolina), described by Smith and Kerr. It is the
fourth meteorite found in South Carolina thus far, the
others being known as the Bishopville (stone), Ches-

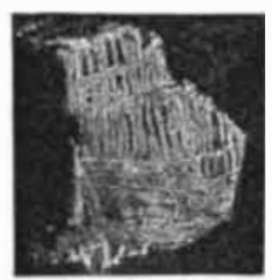

Fig. 3.-Laurens County, S. C., Meteoric Iron

terville, and Ruff's Mountain (Lexington County) meI here extend to $\mathrm{Mr}$. Mackintosh my thanks for his kindness in making the analysis here given, and to $\mathrm{Mr}$
R. W. Milner, of Laurens C. H., South Carolina, for his information as to the history of this very interest ing mass of meteoric iron.

Potassidm Alcoholate.-The author has obtained a coinpound which he names potassium alcoholate. The same name has been applied to compounds of alcohols and bases in which the metal is substituted
for the hydrogen of the alcohol. To avoid confusion for the hydrogen of the alcohol. To avoid confusion
he therefore proposes to reserve for these latter bodie the names of methylates, ethylates, etc. $-R$. Engel, in
WIND AND BAROMETER.

THERE has been quite a lively discussion on this
question, the past few weeks, in Science. This has brought out a number of interesting facts which I desire to briefly state and to add a few cornments. seen from the fact that a paper discussing it was read at the last meeting of the American Association for the Advancement of Science; and quite recently a that at the high station Ben Nevis, in Scotland, the
hat

pressure is frequently lowered $0.10^{\prime \prime}$ in high winds. The by the side of a building produce a partial vacuum in the house sufficient to make an impression upon a
barometer column? If we grant for a moment that an effect will be produced, what will be its nature and characteristics? Of course, the best possible answer under the above conditions. In lieu of these, it seems safe to assume that the direct effect would correspond to the cause, that is, since the wind does not blow less intermittent. The action of the wind is familiar
lore or to every one, and I think that all will admit that in but no absolute cessations. Just the period of the steady action and of the lull cannot be told by an ordinary Robinson anemometer, but may be told by one of Ossler's pattern, which acts by pressure and
gives all the fluctuations. With these fluctuations in mind, we may consider that the effect of a high wind tould be to depress the barometer column almost conmomentary jumps at short intervals. These sudden before the end of the lull and the accompanying sudden fall. In fact, it has been believed by some that it would be impossible to even determine that the wind has any effect at all except by closing up all communication with the room, noting the effect, then opening, noting were established between the cause and the effect. In many very steady winds this would undoubtedly be true, but often it would seem as though the effect of
the lull would be sufficiently marked to be noted by an observer with an ordinary aneroid or even a mercurial barometer. There is also an additional con-
sideration relating to the situation of the chimney or other opening communicating with the room. If this roof, or at the top of a tower, then it might happen that the effect of the wind would be re-enforced, so that of the wind across the chimney, hut also to a tendency to produce a partial vacuum by the air blowing up the

Let us turn to some of the facts that have been thus
far developed. Mr. Clayton of Blue Hill Observatory, near Boston. Mass., some 600 feet above sea level, has noticed some remarkable fluctuations in a self-recording barograph of Prof. Draper's pattern, and has been led produced by the wind, as suggested above. This barograph was situated in the tower of a building at the
summit of the hill. The fluctuations are traced by a pencil attached to a frame holding a barometer tube, which is suspended by two spiral steel springs about a yard in length. The tube of the barometer is free to move up and down, its lower end being immersed in a cistern of mercury, but not fastened to it in any way.
With a wind above forty miles an hour, Mr. Clayton has noticed irregular fluctuations of the pressure trace, which in many instances have a period of two to five minutes from crest to crest of the wave-like oscillations. In many cases the amount of this fluctuation was over $0.05^{\prime \prime}$, and in one case, about the time of opening a trapdoor in the top of the tower, the trace shows a depres-
sion of $0.10^{\prime \prime}$. In the last case, the time interval was over twelve minutes; it would be an interesting fact in this connection if we had given the time the trap-door
was open. In Science for October 8, 1886, we find published a trace of this barograph for three hours, and very near the center of the three hours the above remarkable depression of $0^{\circ} 10^{\circ}$. A study of this trace
shows the characteristics already noticed, that is, a wave-like appearance with a period of two to five minutes. We may add to this the fact that other barographs, of entirely different construction, show the ing only in degree from the one above. In some instances the trace is somewhat different from the one in Science; the trace with an electrical barograph shows a tendency to a movement above as well as below the laid down at the opening of this paper, we must con-
clude that there is nothing in common between this 